\title{
RETINAL CHANGES IN PREGNANCY INDUCED-HYPERTENSION
}

\author{
MANDAR ZADE, V. PANIMALAR A. VEERAMANI*, DIVYA N., BINDU BHASKARAN
}

Department of Ophthalmology, Saveetha Medical College and Hospital, Chennai, Tamil Nadu, India

*Email: drpani07@gmail.com

Received: 15Sep 2020, Revised and Accepted: 17 Nov 2020

\begin{abstract}
Objective: The aim is to determine the prevalence of retinal changes in Pregnancy Induced Hypertension (PIH) and its association with age, parity, proteinuria, blood pressureand severity of PIH.

Methods: This is a tertiary hospital based Cross-Sectional study including all patients, clinically diagnosed with Pregnancy Induced Hypertension. General demographic details along with age, gravida, gestation period, proteinuria, blood pressure and severity of PIH were noted. Ophthalmic examination was performed and detailed fundus examination was done.

Results: A total of 52 patients were included in this study. Their mean age was 24.9 y; 32 out of 52 patients were primigravida (61\%) and 20 patients were multi gravida (39\%). Out of 52 patients $34(65.38 \%)$ had Gestational Hypertension, $16(30.76 \%)$ had preeclampsia, and 2 (3.8\%) had eclampsia. 3 (5.76\%) out of 29 patients with $\mathrm{BP}<160 / 100 \mathrm{mmHg}$ and $10(19.23 \%)$ out of 23 patients with BP>160/100 mmHg had developed Hypertensive Retinopathy. Hypertensive Retinopathy was seen in 13 (25\%). Proteinuria was seen in 10 (19.23\%) patients ranging
\end{abstract} between+to+++on the dipstick.

Conclusion: Statistically significant correlation between retinal changes and proteinuria, blood pressure and severity of Disease.The most important requisite in a case of Pregnancy Induced Hypertension is Fundoscopic examination of retina. The retinal vessels during PIH form a gateway to visualize changes in the body and placental vessels, and may play a key role in early detection and treatment of PIH for protection of the mother as well as the fetus.

Keywords: Blood pressure, Eclampsia, Gestational hypertension, Preeclampsia

(C) 2021 The Authors. Published by Innovare Academic Sciences Pvt Ltd. This is an open access article under the CC BY license (https://creativecommons.org/licenses/by/4.0/) DOI: https://dx.doi.org/10.22159/ijcpr.2021v13i1.40797. Journal homepage: https://innovareacademics.in/journals/index.php/ijcpr

\section{INTRODUCTION}

Pregnancy Induced Hypertension (PIH) is defined as hypertension, with or without proteinuria emerging after $20 \mathrm{w}$ of gestation. It is a disorder of hypertension occurring when no other causes of elevated BP could be found. Preeclampsia is one of the leading causes of perinatal and maternal mortality and morbidity across the world [1, 2]. Its pathophysiology appears to be due to Vascular Endothelial Changes with generalized vasospasm and capillary leak[3]. These changes are usually reversible and briskly returns to normal postdelivery.

PIH is a progressive disease, characterized by Hypertension, significant Proteinuria, and Generalized Edema. If convulsions develop along with rapidly worsening preeclampsia it is known as eclampsia, which canbe life threatening for both the mother and the unbornchild[4].

These vascular changes usually tend to affect the retinal vessels which serves as a window to study the body and placental vessels and their condition[5]. Hence the changes in these retinal vessels might indicate a similar state in the same. Early detection is the pillar to effective treatment and better prognosis of PIH and eclampsia. In this study association between severity of PIH and grades of Hypertensive Retinopathy was established.

\section{Scope of study}

\section{Merits}

By doing this study we have established the relation of various factors with PIH, which can play an important role in early diagnosis, treatment as well as prognosis of PIH cases in the future.

\section{Demerits}

Thedemerits to the study include its short study period, leading to a smaller study group, which was due to the unforeseen circumstances of the Covid-19 pandemic

\section{MATERIALS AND METHODS}

This is a tertiary hospital based cross-sectional study conducted over 3 mo (from January 2020 to March 2020) in Saveetha Medical College and Hospital, Chennai. 52 patients clinically diagnosed as Pregnancy Induced Hypertension were enrolled in the study. Inclusion criterion was clinically diagnosed PIH and willingness to participate in the study. Patients excluded from the study were those with diabetes, pre-existing hypertension, renal disease or patients not willing for examination.

Patient history was taken. Demographics of the patient along with age, gravida, proteinuria, severity of PIH was also noted. PIH was graded as gestational hypertension, preeclampsia, eclampsia. Bedside vision was noted and anterior segment examination was done with torchlight. Fundus examination was done using a direct ophthalmoscope after dilatation of both eyes with $1 \%$ tropicamide eye drops. Both eyes were noted for any changes due to hypertensive retinopathy and were taken as positive findings.

The retinal changes were graded according to Keith Wagener classification into (table 1).

Proteinuria was tested using dipstick method and was graded as provided by manufacturer (table 2).

Table 1: Describes the grades of retinopathy

\begin{tabular}{ll}
\hline Grade of retinopathy & Retinal changes \\
\hline Grade 1 & Mild generalized arterial attenuation, particularly of small branches \\
Grade 2 & More severe Grade 1+focal arteriolar attenuation \\
Grade 3 & Grade 2+hemorrhages, hard exudates, cotton wool spots \\
Grade 4 & Grade 3+optic disc swelling (papilledema) \\
\hline
\end{tabular}


Table 2:Relates the grade of proteinuria with the reading on the dipstick.

\begin{tabular}{ll}
\hline Grade of proteinuria & Reading (mg/dl) \\
\hline+ & $30 \mathrm{mg} / \mathrm{dl}$ \\
++ & $100 \mathrm{mg} / \mathrm{dl}$ \\
+++ & $300 \mathrm{mg} / \mathrm{dl}$ \\
++++ & $\geq 2000 \mathrm{mg} / \mathrm{dl}$ \\
\hline
\end{tabular}

Chi-square test was used to establish the association between the retinal changes and age, parity, proteinuria, and severity of PIH. P value of $<0.05$ was taken as positively significant. Approval from Institute Ethical Committee was taken.

MS Excel was used to analyze and chart the data.

\section{RESULTS}

A total of 52 patients were included in this study. Table 5shows the correlation of age, parity, proteinuria, severity of PIH and blood pressure with retinopathy. Statistically significant positive association between Retinal changes and Proteinuria $(\mathrm{P}=0.039)$, Severity of disease $(P=0.0001)$, Blood pressure $(P=0.015)$. Age $(\mathrm{P}=0.18)$ and Gravida $(\mathrm{P}=0.32)$ did not show positively significant association (as $\mathrm{P}>0.05$ ).

Table 3 represents the details of patients with No Retinopathy, Grade I, Grade II, Grade III and Grade IV hypertensive retinopathy. Most of the patients had No Retinopathy changes.

In table 4 association between grades of hypertensive retinopathy with severity of PIH is established and depicted.

Table 3:Shows the frequency of patients with their grades of retinopathy.

\begin{tabular}{lll}
\hline Grades of retinopathy & Frequency & Percentage \\
\hline No Retinopathy & 39 & $75 \%$ \\
Grade I & 9 & $17.3 \%$ \\
Grade II & 3 & $5.76 \%$ \\
Grade III & - & - \\
Grade IV & 1 & $1.92 \%$ \\
Total & 52 & $100 \%$ \\
\hline
\end{tabular}

Table 4:Shows the relation between grades of retinopathy (according to Keith Wagener classification) and severity of PIH

\begin{tabular}{llll}
\hline Grades of retinopathy & Gestational hypertension & Preeclampsia \\
\hline No Change & 30 & 9 & Eclampsia \\
Grade I & 4 & 5 & - \\
Grade II & - & - & 1 \\
Grade III & - & - & - \\
Grade IV & - & - & 1 \\
\hline
\end{tabular}

Table 5:Shows the association between retinal changes and various factors under study, along with the calculated $P$ values

\begin{tabular}{|c|c|c|c|c|}
\hline Factor & $\begin{array}{l}\text { Retinopathy present } \\
\left(n_{1}=13\right)\end{array}$ & $\begin{array}{l}\text { Retinopathy absent } \\
\left(\mathrm{n}_{2}=39\right)\end{array}$ & $\begin{array}{l}\text { Total } \\
{\left[n=\left(n_{1}+n_{2}=52\right)\right]}\end{array}$ & $\begin{array}{l}\text { P value } \\
(<0.05=\text { significant })\end{array}$ \\
\hline \multicolumn{5}{|l|}{ AGE } \\
\hline$<19 y$ & 0 & 4 & 4 & 0.18 \\
\hline $20-29 y$ & 9 & 31 & 40 & \\
\hline$>30 y$ & 4 & 0 & 8 & \\
\hline \multicolumn{5}{|l|}{ GRAVIDA } \\
\hline Primigravida & 6 & 26 & 32 & 0.32 \\
\hline Multigravida & 7 & 13 & 20 & \\
\hline \multicolumn{5}{|l|}{ PROTEINURIA } \\
\hline No Proteinuria & 7 & 35 & 42 & 0.039 \\
\hline+ & 1 & 2 & 3 & \\
\hline++ & 3 & 2 & 5 & \\
\hline+++ & 2 & 0 & 2 & \\
\hline \multicolumn{5}{|l|}{ SEVERITY OF DISEASE } \\
\hline Gestational hypertension & 4 & 30 & 34 & 0.00001 \\
\hline Preeclampsia & 7 & 9 & 16 & \\
\hline Eclampsia & 2 & 0 & 2 & \\
\hline \multicolumn{5}{|l|}{ BLOOD PRESSURE } \\
\hline$<160 / 100 \mathrm{mmHg}$ (Systolic/Diastolic) & 3 & 26 & 29 & 0.015 \\
\hline$>160 / 100 \mathrm{mmHg}$ (Systolic/Diastolic) & 10 & 13 & 23 & \\
\hline
\end{tabular}

\section{DISCUSSION}

Pregnancy-induced hypertension is one of the commonest causes of morbidity and mortality in obstetrics in the world. 52 patients diagnosed with PIH were included in the study. Mean age in this study was found to be $24.9 \mathrm{y}$ ranging between 19 to $36 \mathrm{y}$. In other studies, like those by Jaeffe and Schatz[6] from US, mean age was 28 y. Majority of the patients in our study were in between 20-29 y (76.92\%), out of which $9(17.30 \%)$ showed hypertensive retinopathy changes. Followed by age group 30-36 (15.38\%) out of which $4(7.69 \%)$ showed retinopathy changes and $19 \mathrm{y}$ and lower $(8 \%)$ with no retinopathy changes. Age in our study does not show 
positive association $(\mathrm{P}>0.05)$ with retinal changes, this finding matches with that of Reddy [7].

In our study, 32 (61.53\%) patients were primigravida out of which 6 (11.53\%) patients developed retinal changes, while $20(38.46 \%)$ were multigravida out of which 7 (13.46\%)developed retinal changes. Retinopathy was found to be 1.2 times more common in multigravida patient than in primigravida, but upon $\mathrm{P}$ calculation the results were not significant $(\mathrm{P}>0.05)$. Hence in our study gravida is not associated significantly with retinopathy changes. This is similar to findings of Reddy [7] and Shah [3].

Out of 52 patients, $34(65.38 \%)$ had Gestational hypertension, 16 (30.76\%) had preeclampsia, and $2(3.84 \%)$ had eclampsia. Similar findings were reported by Shah AP [3], from India, with gestational hypertension in $61.4 \%$, preeclampsia seen in $32.6 \%$ and eclampsia seen in $6 \%$ of 150 patients studied.

Hypertensive retinopathy was seen in 13 (25\%) of the 52 patients. In a study done by Rasdi[8] from Malaysia, found $21.5 \%$ patients to have retinopathy; and the most common retinal finding to be narrowing of fundal arteries. Tadin[9] from Croatia reported 45\% patients with retinal changes.Fundus changes were found in $13.7 \%$ of the subjects in a study by Karki[10] from Nepal. Ranjan[11] and Javadekar[12] both from India reported $40 \%$ and $42 \%$ retinal changes respectively.

Our findings are higher than those of Karki[10], but lower than Ranjan[11], Javadekar[12] and Tadin[9]. Our findings were close to those by Rasdi[8]

Out of 13 (25\%) who developed hypertensive retinopathy, 9 (6\%) patients had Grade-1 Hypertensive Retinopathy, 3 (23.07\%) patients had Grade-2 Hypertensive Retinopathy and only $1(7.69 \%)$ had Grade-4 Hypertensive Retinopathy (Papilledema) as depicted in table 3. None had Grade-3 Hypertensive Retinopathy. In a study done by Jayashree MP [13], they found Grade-1 Hypertensive Retinopathy in $20 \%$ patients, Grade-2 Hypertensive Retinopathy in $0.7 \%$ patients, grade- 3 Hypertensive Retinopathy in $4.7 \%$ patients and grade- 4 Hypertensive Retinopathy in $4.7 \%$ patients.

Grade 3 Hypertensive retinopathy was not found in our study. Acute elevation of blood pressure routinely causes reversible vasoconstriction in retinal blood vessels, and hypertensive crisis may cause optic disk edema. More prolonged or severe hypertension leads to exudative vascular changes and hemorrhages, a consequence of endothelial damage and necrosis. These results show the acute insult caused by rise in Blood pressure.So early and efficient antenatal check-up with detection of retinopathy changes, prompts treatment limits the disease and can prevent further deterioration and permanent damage.

In our study, $4(7.69 \%)$ patients with gestational hypertension, 7 (13.46\%) with preeclampsia and 2 (3.84\%) with eclampsia had developed retinopathy. Chi square calculation produces a significant relation between Severity of Disease and retinal changes ( $\mathrm{P}=0.0001)$ as shown in table 5 .

Table 4 shows the relation between grades of retinopathy and severity of PIH. Grade 1 hypertensive changes were seen in gestational hypertension and pre-eclampsia. Grade 2 hypertensive changes were seen in preeclampsia and eclampsia. Whereas grade 4 was seen only in eclampsia.

Proteinuria was seen in the study, with $10(19.2 \%)$ patients ranging from +1 to +3 on the dipstick. Of the 10 patients $6(11.53 \%)$ developed retinopathy, while only $7(13.46 \%)$ patients out of 42 with no proteinuria had developed hypertensive retinopathy. In our study proteinuria was significantly and positively associated with retinal changes $(\mathrm{P}=0.039)$. These findings were supported by Reddy [7], Shah AP [3].

Out of 29 patients having $\mathrm{BP}<160 / 100 \mathrm{mmHg}$, 3 (5.76\%) developed retinopathy, while 23 patients with $\mathrm{BP}>160 / 100 \mathrm{mmHg}, 10$ (19.23\%) developed retinopathy. On Chi Square calculation, Blood Pressure was hence significantly associated $(\mathrm{P}=0.015)$ with retinal changes. Similar results were reported by Shah AP [3], Reddy [7], Karki[10].

The prognosis in all the above cases was good, with retinal changes coming back to normal spontaneously post-delivery. The signs like papilledema or macular edema may indicate raised Intra Cranial Pressure and may develop as Epileptic convulsions. Therefore, these are the warning signs for medical termination of pregnancy to save the mother's life and sight.

\section{CONCLUSION}

Statistically significant correlation between retinal changes and proteinuria, blood pressure and severity of Disease.The most important requisite in a case of Pregnancy Induced Hypertension is Fundoscopic examination of retina. The retinal vessels during PIH form a gateway to visualize changes in the body and placental vessels, and may play a key role in early detection and treatment of $\mathrm{PIH}$ for protection of the mother as well as the fetus.

\section{ACKNOWLEDGEMENT}

The authors express their sincere thanks to Dr Saveetha Rajesh, The Director of Saveetha Medical College and Hospital, and Department of Obstetrics and Gynecology, Saveetha Medical College and hospital, for their constant motivation and cooperation for this study.

\section{FUNDING}

Nil

\section{AUTHORS CONTRIBUTIONS}

All the authors have contributed equally.

\section{CONFLICT OF INTERESTS}

\section{Declared none}

\section{REFERENCES}

1. Steegers EA, Von Dadelszen P, Duvekot JJ, Pijnenborg R. Preeclampsia. Lancet 2010;376:631-44.

2. Duley L. The global impact of pre-eclampsia and eclampsia. SeminPerinatol 2009;33:130-7.

3. Shah AP, Lune AA, Magdum RM, Deshpande H, Bhavsar D. Retinal changes in pregnancy-induced hypertension. Med J DY PatilUniv 2015;8:304-7.

4. Kintiraki E, Papakatsika S, Kotronis G, Goulis DG, Kotsis V. Pregnancy-induced hypertension. Hormones (Athens) 2015;14:211-23.

5. Roberts JM, Escudero C. The placenta in preeclampsia. Pregnancy Hypertens 2012;2:72-83.

6. Jaeffe G, Schatz H. Ocular manifestation of preeclampsia. Am J Ophthalmol 1987;103:309-15.

7. Reddy SC. Ocular fundus changes in toxemia of pregnancy. Antiseptic 1989;86:367-72.

8. Rasdi AR, Nik-Ahmad-Zuky NL, Bakiah S, Shatriah I. Hypertensive retinopathy and visual outcome in hypertensive disorders in pregnancy. Med J Malaysia 2011;66:42-7.

9. Tadin I, Bojic L, Mimica M, Karelovic D, Dogas Z. Hypertensive retinopathy and pre-eclampsia. CollAntropol 2001;25 Suppl:77-81.

10. Karki P, Malla P, Das H, Uprety D. Association between pregnancy-induced hypertensive fundus changes and foetal outcomes. Nepalese J Ophthalmol 1970;2:26-30.

11. Ranjan R, Sinha S, Seth S. Fundus changes and fetal outcomes in pregnancy induced hypertension: an observational study. Int J Sci Stud 2014;2:6-9.

12. Javadekar SD, Javadekar DP, Joshi K, Khatiwala R. Fundoscopic changes in pregnant mother with hypertension complicating pregnancy and various parameters of fetus. Int J Recent Trends SciTechnol 2013;7:110-3.

13. Jayshree MP. Ocular fundus changes in pregnancy induced hypertension-a case series study. J Clin Res Ophthalmol 2018;5:37-41. 